\title{
NAAR EEN ORGANISATIONELE THEORIE VAN STRATEGISCH HANDELEN
}

\author{
door Dr F. Haselhoff
}

\section{Aanvaarding en reductie van onzekerheid}

Organiseren heeft niet helemaal ten onrechte een dubbelzinnige betekenis. Het heeft een negatieve klank vanuit een ingeboren angst bij iedereen voor allesbe. heersende ordening, die ten koste gaat van de vrijheid van het individu. Aan de andere kant wordt organiseren ook gezien, vanuit een onvrede met sociale ongelijkheid, als een mogelijkerwijs positieve bijdrage tot realisatie van een stukje gerechtigheid. Juist omdat organisaties doelverwezenlijkende systemen zijn, ligt het voor de hand, dat ze vanuit de samenleving erg vatbaar zijn voor kritiek. Een belangrijke vraag is in hoeverre aan die verlangens moet worden tegemoet geko. men. Een strategische vraag bij uitstek.

In onze samenleving heeft zich die tweeërlei druk op organisaties steeds dui delijker geprofileerd. De toenemende drang naar vrijheid van alle bij organisaties betrokken partijen is vooral sterker geworden door de welvaartsstijging, die de mensen het gevoel heeft gegeven hun lot meer in eigen handen te kunnen nemen. Maar het tegengestelde is ook waar. Door de groeiende dynamiek en complexiteit van de maatschappij is het gevoel van onbehagen omtrent bestaande onevenwichtigheden in welvaart en welzijn sterker geworden. Zo wordt aan de moderne organisatie de eis gesteld tegelijkertijd aan de vrijheid van consumptie en van arbeid gestalte te geven als het welzijn van alle betrokkenen op een rechtvaardige manier veilig te stellen.

Organisaties die zichzelf respecteren en deze verlangens ernstig proberen te ne. men, balanceren juist daardoor maar al te dikwijls op het scherp van de snede. Te veel vrijheid geven aan degenen, die bij de organisaties betrokken zijn, d.w.z. aan de organisatieleden, aan de afnemers, aan de leveranciers, aan de overheid en aan de bewoners van de regio kan gemakkelijk leiden tot een zo grillig gedrag, dat onvoldoende ruimte overblijft voor een min of meer consistente planning op lange termijn. Van een doelmatig organisationeel gedrag kan dan slechts in be. perkte mate sprake zijn. Er moet dan in de organisatie te veel flexibiliteit worden ingebouwd. Aan de andere kant kan een teveel aan al of niet bestaande, maar toch vermeende ongerechtigheid willen opheffen een organisatie te zwaar belas. ten met beloften, die ze niet in alle omstandigheden kan waarmaken. In feite heeft dan de betrokken organisatie zich opgescheept met een tekort aan flexibiliteit. In het eerste geval is een te grote mate van onzekerheidsaanvaarding getole. reerd, in het andere is er een teveel aan onzekerheidsreductie. In beide gevallen komt de overleving van de organisatie op de tocht te staan.

\section{Doelmatigheid, overleving en zingeving}

Hoe breed de begaanbare weg hier in de concrete situatie is, hangt af van de ka. 
rakteristiek van de omgeving, waarin de organisatie zich moet handhaven. Met die overlevingsproblematiek zal een organisatie namelijk niet zoveel moeite heb. ben als de omgeving op zichzelf al betrekkelijk stabiel is. Dan is er nauwelijks spra. ke van bedreigende onzekerheden. Maar de dynamiek, de complexiteit en de conflictdreiging in onze samenleving is door ontwikkelingen van schaalvergroting, technologie, communicatie, welvaartsstijging en democratisering zodanig, dat de moderne organisatie met dit stabiliseringsprobleem algemeen gesproken grote moeite heeft.

Hoewel met het rationaliteitscriterium van de overleving een belangrijk oriëntatiepunt voor organisationeel gedrag is aangegeven, is daarmee toch niet alles gezegd. Een organisatie dient daarnaast ook puur technisch gesproken te functioneren. Als dat in concurrentie gebeurt met andere organisaties zal de daardoor aan het licht komende schaarste van middelen vergen, dat op een economisch doelmatige wijze gefunctioneerd wordt. En verder zal de organisatie als sociaal sys. teem ook tot op zekere hoogte de zingeving van de betrokkenen moeten dienen. Anders zou er immers onvoldoende motivatie tot functioneren kunnen worden opgeroepen. Op grond van deze overwegingen is organiseren een vraagstuk van doelmatigheid, van overleving en van zingeving.')

Doelmatigheid is een zodanige afstemming van middelen op doeleinden, dat op een aanvaardbare wijze met schaarste van die middelen is rekening gehouden. De organisatie wordt daartoe beschouwd als een geheel van oorzaken en gevol. gen, die door de beslisser worden gezien als respectievelijk bruikbare middelen en na te streven doeleinden. Dit is het paradigma van het dingmatige decisie- en actiemodel, dat op de toekomst is georiënteerd. Juist die openheid naar de toe. komst plaatst het beslissen voor onzekerheden in de vorm van onvoorziene ver. anderingen in de determinanten voor de besluitvorming. Wil men via die besluitvorming daadwerkelijk aan de organisationele actie gestalte geven, dan zal die onzekerheid moeten worden overwonnen door adequate informatie over de situa. tie. Strategische actie wordt binnen dit paradigma geheel beheerst door een gecoördineerd strategisch plan.

Overleving is handhaving in een omgeving, die een groot aantal kansen en bedreigingen inhoudt. Deze moeten worden uitgebuit respectievelijk worden gepareerd. De organisatie verschijnt hier als een geheel, dat via „inputs” en „outputs” relaties met haar omgeving onderhoudt. Dit is het paradigma van het open systeem. Onzekerheid neemt de gestalte aan van complexiteit van de omgeving, die slechts kan worden overwonnen door complexiteitsreductie, d.i. het opbouwen van or. ganisationele macht. Pas dan kan de organisatie een bepaalde autonomie verkrijgen tegenover de veelheid van mogelijkheden. Dat betekent overigens wel, dat een deel van die omgevingscomplexiteit zich zal manifesteren in het complexiteitskarakter van die organisatie zelf. Deze complexiteitsaanvaarding maakt een organisatie tot een flexibel systeem, dat beter tegen de onzekerheden uit de omgeving is opgewassen. Strategische actie wordt daardoor beheersing van een open systeem.

Zingeving speelt zich af in de sociale dimensie en richt zich op de leefbaarheid van de organisatie voor de betrokkenen, zowel binnen als buiten, tot uitdrukking

\footnotetext{
') F. Haselhoff. Ondernemingutralegie, een dilemma be moderne ondememingsorganisatie in het spamningsveld van dow/matigheid, overloving en zingeving. Alphen a/d Rijn. Samsom. 1977
} 
gebracht in een min of meer consistent geheel van doeleinden en waarden. Dit paradigma is het model van menselijke discussie en interactie. Onzekerheid vindt haar uitdrukking in conflict en dreiging van conflict tussen mensen. Hier is nodig het tot stand brengen van een zekere consensus tussen de van huis uit uiteenlopende motivaties van de betrokkenen. Strategische actie ontvangt hierdoor haar legitimatie.

\section{Strategische planning}

Het is vooral de economische ondernemingstheorie, de „economic theory of the firm", die op het terrein van strategie belangrijke aanzetten heeft geleverd voor het eerstgenoemde decisiemodel. Men ging daarbij uit van de enkele handeling, van één actor (het zogenaamde „unibrain”), van een vooraf gedefinieerd doel (t.w. de maximale winst), van beschikbare middelen, van te respecteren condities en van alternatieve keuzemogelijkheden. De tekortkomingen van dit model vanuit het standpunt van de organisatiewetenschap liggen vooral in

- de ene actor, waardoor de organisatie een louter instrumentele rol speelt,

- in het winstdoel, waardoor de geldsluier andere doelen verhult,

- in de veronderstelde zekerheid met betrekking tot de geïnformeerdheid van de actor, waardoor het model gesloten is,

- in het onderploegen van de dynamiek van de organisationele actie en

- in het uiteindelijk gedetermineerde karakter van de beslissing.

Richten we ons nu eerst op dat deterministische karakter van deze theorie. Een meer voluntaristisch actieconcept ${ }^{2}$ ) dient om te beginnen afstand te nemen van al te eenvoudige gedragsveronderstellingen. Daarbij zijn immers te veel condities gefixeerd, waardoor te weinig variabelen als echte operatoren van de actie overblijven. Bovendien is de doelfunctie dan meestal te weinig genuanceerd om psy. chologisch aanvaardbaar te zijn. Het eerste wat dient te gebeuren is de mate van geinformeerdheid van de beslisser als een variabele op te vatten. Dat schept ruim. te voor echte besluitvorming onder onzekerheid. Verder zal Simon's veronderstelde interactie tussen aspiratieniveau met betrekking tot doeleinden enerzijds en de perceptie van de situatie anderzijds moeten worden ingebouwd ${ }^{3}$ ). Daardoor ontstaat het zogenaamde open-satisfactiemodel van het beslissen. Het zoeken naar informatie in plaats van de veronderstelling van volledige geïnformeerdheid wordt dan een aparte variabele afhankelijk van de mate van onvrede, die de beslisser met de aangetroffen situatie heeft.

Ansoff heeft deze noties in zijn strategische theorie verwerkt ${ }^{4}$ ). Zijn "quasi-analytische" decisietheorie levert het instrumentarium om zogenaamde "ill-structured problems" aan te kunnen. Zijn organisatiebeeld van de onderneming tot uit. drukking gebracht in een doeltheorie en een planningtheorie blijft echter nog aan de magere kant. De „black box” van het ondernemingssysteem wordt nog onvoldoende wit gemaakt.

\footnotetext{
1) Talcott Parsons. The Structure of Social Action: A Study in Social Theory with Special Reference to a Group of Recent European Writers $(2$ delen). New York, Free Press, 1968 (oorspr. 1937), pp 81 e.v.

) Herbert A. Simon. Administrative Behavior. A Study of Decision-Making Processes in Adminutrative Organizations (2nd ed). New York, Macmillan, 1957, pp. xxiv e.v. en pp. 80 e.v. Vgl. ook: James G. March en Herbert A. Simon. Organizations New York, Wiley, 1958, pp. 47 e.v.

4. H. Igor Ansoff. A Quasi Analytic Approach to the Business Strategy Problem. Management Technology, 1964, Vol 4, No 1. pp. 67.75; H. Igor Ansoff. Corpurate Strategy: An Analytic Approach lo Business Policy for Grouth and Expansion. Harmondsworth, Pen guin Books, 1968 (oorspr. ! 965 )
} 
Ansoff's weliswaar in eerste instantie gedifferentieerde doelbegrip, onderge bracht in een doelenhiërarchie, blijkt bij nadere beschouwing toch een geheel economisch bepaald ondernemingsbeeld in te houden. Dat neemt niet weg, dat zijn ,proxies”, opgevat als remplaçanten van het winstdoel, een vruchtbare nuan. cering van het doelbegrip mogelijk maken. Toch schuift hij te veel de niet-economische doelen naar de marge van zijn theorie.

Ook de onzekerheid, in Ansoffs termen ,partial ignorance”, wordt weer via de veronderstelde mogelijkheid tot anticipatie, zij het op betrekkelijk hoog abstrac. tieniveau, van toekomstige ontwikkelingen tenietgedaan. Maar ook hier is toch een belangrijke stap voorwaarts gedaan in zijn nuancering van het ondernemingsgedrag tot een theorie van „entrepreneurial planning”. Wel blijft onderne mingsstrategie via de veronderstelde "single actor" nog een pure management. aangelegenheid. De rationaliteit van het ondernemingsgedrag steunt geheel op psychologische gedragsveronderstellingen van de zogenaamde „change generating manager", die een hoog aspiratieniveau en een allesomvattende beslissings. kracht zou hebben. Die beslisser doet a.h.w. een ambitieuze greep naar de juiste strategie, waardoor de organisationele dynamiek van interne besluitvormings. processen op de achtergrond blijft. Zowel naar de volgtijdigheid als naar de ge lijktijdigheid is deze decisietheorie te arm aan inhoud om met de werkelijkheid van het ondernemingsgebeuren te stroken. Vanwege de rationalistische instel ling van Ansoff is de uitkomst, zij het dan met behulp van een meer „,sophisticated" proces van strategische besluitvorming vergeleken met de „economic theory of the firm", toch weer in hoge mate gedetermineerd. Met name de problemen rondom de implementatie van de gekozen strategie komen onvoldoende aan hun trekken.

Ansoff's denkbeelden omtrent ondernemingsstrategie, althans zoals ze waren neergelegd in zijn „Corporate Strategy” uitgekomen in 1965, vormen een theorie van strategische planning, die in de dagelijkse praktijk nog veelvuldig opgeld doet. Mijn kritiek is meer bedoeld tegen die praktijk dan tegen Ansoff zelf. Dit des te meer, omdat hij er later duidelijk blijk van heeft gegeven, dat zijn vroegere theorieën ontoereikend waren ${ }^{5}$ ). Of hij erin geslaagd is om deze op een adequate wijze uit te bouwen, blijft echter een open vraag.

\section{Strategische macht}

De conclusie is gerechtvaardigd, dat complexiteit en contingentie van de omgeving niet uitsluitend met behulp van zogenaamde strategische planning kan worden overwonnen. Daarvoor is meer nodig. Een eerste stap is het decisie- en actiemodel op te nemen in een ruimer en effectiever paradigma. Dat betekent in de eerste plaats, dat de onzekerheid en daarmee het tekort aan informatie werkelijk serieus wordt genomen. Een organisatie zal immers voortdurend haar besluitvorming na invoering van de daaropvolgende actie aan onvoorziene, gewijzigde omstandigheden, d.i. aan andere dreigingen en kansen moeten aanpassen. De anticipatie, het vooruitlopen op de toekomst is in verband met die onzekerheid maar al te vaak onbetrouwbaar.

\footnotetext{
5) Vgl H. Igor Ansoff, Roger P. Declerck en Robert L. Hayes. From Strategic Planning to Strategic Management. Londen, Wiley, 1976, pp. 29.78.
}

$m a b \quad b l z 30$ 
Dat aanpassen zal gedragen moeten worden door voortdurend veranderende organisatieprocessen en -structuren, kortom door een dynamisch open systeem. Dat maakt het zogenaamde open-systeemparadigma onmisbaar. Anders gezegd, de tekortschietende doelrationaliteit dient te worden opgevangen in de systeemra. tionaliteit. Het is een continu putten uit de talloze mogelijkheden en een keren van de talloze dreigingen, die in de omgeving opdoemen: een proces dat wordt aangeduid met de term complexiteitsreductie. Problemen worden zo nooit geheel definitief tot oplossing gebracht; ze planten zich als het ware door systeem en omgeving voort.

Dat een dergelijk open systeem zich toch zal moeten handhaven, stelt het machtsprobleem aan de orde ${ }^{6}$ ). Met behulp van die macht kan een organisatie zich stabiliseren, zij het door verandering heen. Dat betekent, dat de organisatie tel. kens bedacht is op het hebben van steunpunten in de omgeving. Dit zijn op hun beurt weer richtpunten in de zin van haalbare doeleinden, ook wel het domein van de organisatie genoemd. De segmenten van de omgeving, waarop die doeleinden zich richten zijn de zogenaamde taakomgevingen. De organisatie lijkt in dit opzicht op een jongleur, die een groot aantal ballen op een gecontroleerde wijze in de lucht moet houden. Ze houdt daardoor een energiebalans in stand, die ervoor zorgt dat er per saldo uit de verschillende takkomgevingen meer energie wordt toegevoerd dan eraan wordt afgegeven. Ze zal zich macht uit de omgeving moe. ten laten aanleunen, maar ook macht naar buiten moeten uitoefenen.

Uiteraard komt het vooral op die machtsbeïnvloeding aan. Op grond van de „power-dependence”-theorie van Emerson') kan worden gesteld, dat afhankelijkheid van een betrokkene in een taakomgeving recht evenredig is met het belang, dat men heeft bij waarden, die die betrokkene wil afgeven en omgekeerd even. redig met de beschikbaarheid van die waarden elders. Men moet in het geval, dat men een machtspositie inneemt er echter ernstig mee rekenen, dat de zwak. kere partij de keus heeft uit een viertal tegenacties, t.w. het zich terugtrekken, uit. breiding van zijn macht over derden, het vormen van tegenmacht in de vorm van een coalitie met derden en het uniek maken van de door hem af te geven waar. den door de status-waarde ervan te verhogen ${ }^{8}$ ).

Door de problematisering van de anticipatie is besluitvorming niet slechts een kwestie van vooruitziend plannen, maar ook van achteraf sturen en leren. Organisationeel gedrag is meer dan „prearranged behavior”, het is ook „contingent be. havior" ${ }^{\prime \prime}$. Onzekerheid maakt terugkoppelingsprocessen nodig op grond van in. middels tijdens of na de actie verkregen additionele informatie. Dat maakt nu juist de dynamiek van de organisatie uit. Er is sprake van overleven-door-verandering. heen. Het besturingsparadigma en het overlevingsparadigma zijn complementair. Het decisie- en het systeemmodel worden zo op elkaar betrokken.

Het beslissingsmodel wordt daarmee uiteraard veel gecompliceerder dan de enkele handeling als model toeliet. Een complicering, die vraagt om het zogenaamde ,interface"-model. Het ,interface” is te beschouwen als ontmoetingspunt

\footnotetext{
4) Vgl James D. Thompson. Organizations in Action: Social Science Bases of Administrative Theory. New York, McGraw.Hill, 1967 , p. 30 e.v.

7) Richard M. Emerson. Power. Dependence Relations, American Sociological Review, 1962, Vol 27, Pp. 31 I

8) Id., pp. 35 e.v.

7) Norbert Wiener. The Human Use of Human Beings: Cybernetics and Soctety (2nd rev. ed.). New York. Doubleday (Anchor Books), 1954, p. 22.
} 
tussen ,inner” en „outer environment”"10). Hierin kan het middel-doelmodel van het decisieparadigma in combinatie met het ,input-output"-model van het open systeem aan zijn trekken komen. Ze worden erdoor zelfs aan elkaar gekoppeld. Dat wordt voor een belangrijk deel gerealiseerd door het op één lijn stellen van doelen en nevenvoorwaarden. Beide zijn immers ,value premises that can serve as input to decisions"'). Ze stellen beide grenzen aan de oplossing van een probleem.

Deze gelijkschakeling van doelen en nevenvoorwaarden levert het veel bruik. baarder begrip ,multiple criteria” of ,multiple goals” op. Deze zijn zowel volgtijdig als gelijktijdig richtpunten van organisationele actie. Het wordt nu ook mogelijk inconsistentie op te vangen. Men kan namelijk allereerst zijn toevlucht nemen tot een scheiding in de tijd door middel van volgtijdige waardenverwezenlijking, maar daarnaast ook tot het onafhankelijk maken van subsystemen en zo gelijk. tijdig niet geheel onderling verdraagzame waarden verwezenlijken. Uiteraard lukt dat niet altijd, waardoor we met ernstige dilemma's in de organisationele be. sluitvorming kunnen worden geconfronteerd. Het begrip strategisch krijgt er een betekenis bij, namelijk die van een beperkende factor. Verandering van een dergelijke factor is immers essentieel (vergelijk Ashby's „essential variables”-1) voor de overleving van het systeem. Niet alle doeleinden en nevenvoorwaarden zijn even belangrijk op dit punt. Bovendien verschuift die belangrijkheid in de tijd ge. zien. Deze relativering van het doelbegrip of van het waardebegrip is een kenmerk van het open-systeemdenken. Er is in tegenstelling tot het aanvankelijk gesloten model nu ruimte gecreëerd voor een open decisie en actiemodel.

Stabilisering van een organisatie is zo een zeer ingewikkelde aangelegenheid van onzekerheidsreductie geworden met tegelijkertijd als belangrijke variabelen informatie en macht. Die onzekerheidsreductie hangt met betrekking tot de besluitvorming, waarbij informatie centraal staat, af van de veranderlijkheid van de decisieomgeving, d.i. van de beslissingsfactoren; met betrekking tot het machtsevenwicht, dat in het open-systeemdenken de belangrijkste rol speelt, van de complexiteit, d.i. van de dreigingen en kansen vanuit de systeemomgeving.

\section{Technologie en omgeving als conditionering}

In aansluiting hierop moeten we nu twee belangrijke determinanten van het organisationeel gedrag introduceren, t.w. de technologie en de omgeving, respectievelijk in de betekenis van die decisie-omgeving en van die systeemomgeving. Met technologie wordt dan ook de conditie van de beschikbare informatie aangeduid, met omgeving die van de macht van het systeem. Uiteraard ligt het draaipunt in beide gevallen bij de mate van onzekerheid.

Perrow heeft de aard van het besluitvormingsproces afhankelijk gemaakt van een viertal technologietypen ${ }^{13}$ ). Hij analyseert daartoe de aard van de stimuli tot beslissen. Stimuli kunnen enerzijds vertrouwd of niet vertrouwd zijn, anderzijds homogeen of heterogeen van karakter zijn. De eerste typering bepaalt of het besluit-

10, Vgl Herbert A. Simon. The Sciences of the Artifictal. Cambridge, M.I.T. Press, 1969, p. 7

1) Herbert A. Simon. On the Concept of Organizational Goal. Administrative Science Quarterly. 1964 (juni). [2. 3

1) W. Ross Ashby. An Introduction to Cybermetics Londen, Chapman and Hall, 1956, 1). 197

13) Charles Perrow: Organizational Analysis A Sociological View. Londen. Tavistock, 1970. pp. 75 e.v. 
vormingsproces al of niet gestandaardiseerd kan worden. Dit is van invloed op de intensiteit van zoekprocessen tijdens de actie ${ }^{1+}$ ). De tweede typering bepaalt of er sprake is van weinig of van veel uitzonderingsgevallen. In een vierkantstabel uitgezet levert deze analyse vier technologietypen op, t.w. „routine”, „non-routine", ,craft" en ,engineering"'5).

Achter deze technologie liggen machtsverschijnselen, die zich tussen systemen respectievelijk subsystemen en hun omgeving afspelen. Emery en Trist hebben de aard van het besluitvormingsproces (planning c.q. leren) en van de machtsuit. oefening dan ook afhankelijk gemaakt van een viertal omgevingstypen $\left.{ }^{16}\right)$. Zij analyseren daartoe vooral de bereikbaarheid en de vermijdbaarheid van respectie. velijk de „goods” en de „bads” in die omgeving. In begrippen, die nagenoeg voor zichzelf spreken onderscheiden ze vier typen, t.w. „placid, randomized”, „placid, clustered”, „disturbed, reactive” omgevingen en „turbulent fields”.

In aansluiting op de twee typologieën van technologie en omgeving zijn twee stabiliseringsstrategieën, t.w. met betrekking tot informatieverwerking en met betrekking tot machtsuitoefening van belang. De ene groep betreft technologische strategieën, waarbij coördinatie van middelen op een doel centraal staat, de an dere groep betreft ecologische strategieën, waarbij adaptatie en beheersing voorop staat. Door deze strategieën tegelijkertijd toe te passen, schuiven de middel.doel. benadering en het ,input-output"-model in elkaar tot één open-systeemvisie van het organisatieverschijnsel.

\section{Technologische stabilisering}

Technologische stabilisering is gericht op de besluitvorming nodig ter doelmatige afstemming van middelen op een vooraf gestelde grootheid, dat als doel wordt gezien. Er kan worden onderscheiden tussen anticipatiestrategieën en leerstrate. gieën. Anticipatiestrategieën kunnen een bepaald programma nauwkeurig in de tijd vastleggen, maar dit komt zelden als mogelijkheid voor. Er zijn practisch altijd ver. storingen, die om conditionele programma's ${ }^{17}$ ) vragen. Maar in die laatste kan toch ook nog een belangrijke hoeveelheid anticipatie verborgen zitten. Het zijn namelijk programma's die op basis van verwachte storingen beschikbaar worden gesteld. Het tijdstip, waarop een dergelijk programma moet worden uitgevoerd blijft open: het is tijdsindifferent. Men weet namelijk niet nauwkeurig wanneer die storingen optreden, hoogstens de kans waarmee dat gebeurt. Anticipatie. strategieën zijn voor een belangrijk deel gebaseerd op ervaringen uit het verle. den. Dat laatste leidt tot leergedrag. Er zijn dan ook veranderingen in die anticipatiestrategieën mogelijk. Daarbij kunnen leerstrategieën behulpzaam zijn. De aanzet voor leren ligt in ,problem solving”, namelijk op het moment dat routines het laten afweten. Tijdens de actie dient men dan informatieverwerking te plegen, evenzovele ervaringen met nieuwe situaties. Deze worden in het geheugen

\footnotetext{
14) Jay Galbraith. Designing Complex Organizations. Reading. Addison Wesiey. 1973, p. 4

15) Perrow, 1970, p. 98

is) F. E. Emery en E. L. Trist. The Causal Texture of Organizational Environments. In: F. E. Emery (ed). Systems Thinking: Selected Readings Harmondsworth, Penguin Books, 1969, pp. 241257

1). Niklas Luhmann. Zuteckbegriff und Systemrationalität: Ueber die Funktion won Zuecken in sozialen Systemen. Tübingen, Mohr. 1968, pp. 166 c.v.; Niklas Luhmann. Lob der Routine (1964). In: Idem. Politische Planung: Aufsatze zur Soziologie van Politik und V'erwaltung Opladen, Wesideutscher Verlag, 1971. pp. 113.142
} 
opgeslagen en kunnen zonodig tot nieuwe geanticipeerde conditionele program. ma's leiden. Maar de beslissingssituatie kan zo onzeker zijn, dat er in belangrijke mate blijvend op „problem solving" een beroep moet worden gedaan. Er is dan sprake van leren op een hoger abstractieniveau, d.w.z. men leert problemen op te lossen op basis van een zogenaamd doelprogramma, waarmee een betrekke. lijke grote speelruimte tot beslissen overblijft ${ }^{18}$ ).

\section{Ecologische stabilisering}

Ecologische stabilisering is gericht op een zodanige machtsuitoefening, dat de energiebalans van ,input" of "output" in eigen voordeel omslaat, waardoor de overleving van het systeem wordt gediend. Er kan hier worden onderscheiden tussen concurrentiestrategieën en samenwerkingsstrategieën. Meent men geheel uit eigen kracht zich te kunnen handhaven, dan zal men de eerste strategie kiezen. Men dingt daarbij in concurrentie met anderen naar de gunsten van een derde partij. In het algemeen werkt men hierbij aan zijn eigen prestige. Dat kan zijn gebaseerd op wezenlijke en minder wezenlijke eigenschappen van de eigen prestaties. Als de derde partij er maar gunstig op reageert. Samenwerkingsstrategieën gaan uit van de erkenning, dat er op bepaalde punten sprake is van complementariteit met een andere partij. Men tracht zijn zwakke zijde te compenseren door de beschikking te krijgen over de medewerking van een andere op dit punt sterkere partij. Wil dit lukken dan zal men zelf uiteraard sterke punten moeten hebben, die de ander mist. Samenwerkingsstrategieën kunnen de vorm aannemen van het sluiten van een contract, van het plegen van coöptatie of van het vormen van een coalitie met de andere partij ${ }^{19}$.

\section{Een systeem van subsystemen}

Wil dit ingewikkelde samenstel van strategieën inderdaad tot overleving van de organisatie bijdragen, dan is het belangrijk de organisatie in haar ware gedaante te analyseren, namelijk als systeem van subsystemen. De „black box” dient te wor. den geopend. Strategie zal namelijk zorgvuldig moeten inspelen op de structuur van een organisatie en omgekeerd. Er is sprake van een wisselwerking tussen beide. Door de onderkenning van die subsystemen wordt een organisatie een dynamisch, complex geheel van "interfaces" in plaats van de ene ,interface” tussen ,inner" en „outer environment”. Ook op elk van die „interfaces” hebben de zojuist genoemde technologische en ecologische strategieën betrekking. Die subsystemen dienen zo geordend te zijn, dat de organisatie zich overeenkomstig de heersende, overigens van plaats tot plaats en van geval tot geval verschillende technologie en omgeving op een lijn plaatst tussen "organized simplicity” en "chaotic complexity". Dat zal in het geval van onzekerheid neerkomen op een vorm van

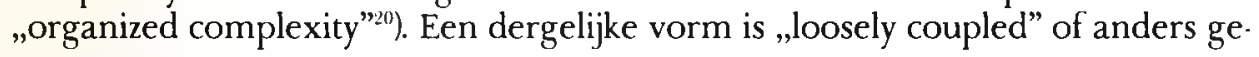

\footnotetext{
18) Vgi Gaibraith. 1973. pp. 12 e.v.

19) Thompson, 1967, pp. $35 / 36$

20) Warren Weaver. Science and Complexity. American Scientist, Vol 36 (1948). pls. 536.544; Anatol Rapopon en William J. Horvath. Thoughis on Organization Theory (1959). In: Walcer Buckley (ed). Mixdern Systems Research for the Beharioral Scienlist: A Sourcebook Chicago, Aldine, 1968, p|. 71.75
} 
zegd ,nearly decomposable"'1!), d.w.z. ze is zelf behept met onzekerheden en met vrijheidsgraden van handelen. Dat maakt haar tegelijkertijd flexibel en effectief.

Maken we de balans op van ons inmiddels uit de eerste twee paradigma's op. gebouwd organisatiebeeld, dan kunnen we zeggen, dat hoewel subsystemen zijn zichtbaar geworden, de dominantie van het management, dat die subsystemen tot één geheel samensmeedt, is gebleven. Maar er is ook iets boven water gekomen omtrent het „capability”-probleem van de organisatie. Er is iets zichtbaar geworden van het verschijnsel van de "multiple actors” binnen de organisatie. Sub. systemen gedragen zich tegenover elkaar op een semi-autonome wijze. Het sa. menspel tussen die substemen-actors is nu een meer dringende kwestie gewor. den. De vraag komt op, hoe de versplinterde problemen en de versplinterde macht tot een minimaal consistent geheel wordt. Daarvoor is het laatste paradig. ma, dat de sociale dimensie in kaart brengt, onontbeerlijk.

\section{Strategische legitimatie}

De sociale dimensie komt tevoorschijn in het menselijk discussie- en interactiemo. del. Ze legt de bronnen van onzekerheid in en rondom een organisatie bloot door de zingeving en daarmee de dissensus vanuit het gezichtspunt van de „stakehol ders", van alle bij de organisatie betrokken mensen, aan de orde te stellen. Hierbij wordt de „black box” van het systeem inderdaad verder ontsloten. Op het eerste gezicht lijkt hier het coalitiemodel te passen, dat zegt: „people (i.e. individuals) have goals; collectivities of people do not"2 ${ }^{2}$ ). Het maakt de concrete participanten op het eerder genoemde "interface" en hun uiteenlopende motivaties en doelstellingen zichtbaar. Bij nadere beschouwing blijkt echter, dat het coalitiemodel op zichzelf niet veel meer is dan een elementaristische decisietheorie. Als zodanig opent het onvoldoende zicht op het sociaal systeem. Er moet namelijk een koppeling met de andere twee paradigma's worden gemaakt: de organisatie als sociaal systeem dient het decisiemodel en het open systeemconcept als het ware in zich op te nemen. Pas dan kan aan de besluitvorming in organisaties werkelijk steun worden gegeven.

Het is met name de vaststelling van aanvaardbare grenzen van systeem en subsystemen, alsmede het formuleren van gefundeerde gedragsverwachtingen, die de verbrokkeling van de organisationele actie tegenwerken ${ }^{23}$ ). Daarvoor zijn alledrie werkelijkheidsdimensies nodig: organisationele actie wordt vanuit een doel doelmatig, vanuit omgevingseisen levensvatbaar en vanuit de mens zinvol ge. maakt. Tot het laatste dient dan vooral de sociale dimensie. Belangrijk is, dat de organisatie daardoor min of meer tot een consistent, stabiel en harmonisch geheel van actie wordt. Min of meer, omdat een organisatie veelal een relatief inconsistent, instabiel en conflictgeladen karakter blijft houden. De sociale dimensie maakt plausibel, dat organisatieproblemen in laatste instantie problemen van mensen zijn.

Omdat het sociale paradigma loopt over de verwachtingen van de betrokken individuen, waardoor normatieve institutionalisering van organisationeel hande-

\footnotetext{
21) Simon, 1969, pp. 99 e.v.

22) Richard M. Cyert en Jaines G. March. A Beharurial Theon of the Firm. Englewood Cliffs, Prentice-Hall. 1963, p. 26

-3 ) Luhmann spreekt respectievelijk van "Grenzsetzung" en van "Generalisierung von Verhaltenserwartungen" (vgl Luh. mann, 1970, p. 125)
} 
len wordt mogelijk gemaakt, dienen we ons te verdiepen in de persoonlijke motieven en de professionele doelen van de participanten, respectievelijk in de „decisions to participate" en in de "decisions to produce"-4). Twee met elkaar samenhangende beslissingssituaties van iedere "stakeholder” in een organisatie. De een stelt het "commitment", dat hij of zij wil aangaan ter discussie en is een vorm van markthandelen. De ander gaat uit van een geaccepteerde „zone of indifference”-5) met betrekking tot zijn of haar motivatie en is organisatiehandelen. De dreiging voor iedere organisatie is, dat de participanten vanuit organisatiehandelen kunnen te. rugvallen in markthandelen. Dat gebeurt als over de „rewards” en "contributions", over de beloningen en de bijdragen geen overeenstemming meer bestaat. Informatie en macht zijn bij dit consensusprobleem weer belangrijke variabelen, waardoor alledrie paradigma's werkzaam blijven. Hier wordt het doelstellingsprobleem in volle omvang aan de orde gesteld.

\section{Sociale strategieën}

Vanuit dit omvattend perspectief worden dan ook met name daarop aansluitende sociale strategieën vereist. Vanuit het handelen, waarbij de macht een belangrijke variabele is, zijn er onderhandelingsstrategieën vanuit de organisatie in de richting van de „stakeholders” nodig. Vanuit het denken, waarbij informatie de overheersende variabele is, is er een "organisationele filosofie" wenselijk. De ene strategie maakt het welbegrepen eigenbelang via interactie of ruil van de betrokkenen tot draaipunt, de ander het elkaar aanspreken, het elkaar overtuigen via discussie. De eerste groep strategieën laat zich onderverdelen in recruteringsstrategieën, conflictstrategieën en veranderingsstrategieën. Recruteringsstrategieën regelen de toe. treding en de uittreding van participanten, ook van de niet-leden. Dissensus hoeft niet altijd tot uittreding te leiden. Vandaar dat daarnaast de organisatie conflictstrategieën zal ontwikkelen, die zich vooral richten op het tot elkaar brengen van verschillend gerichte aspiraties van de betrokkenen. Naast de mechanismen van toetreding en uittreding, alsmede het wijzigen van aspiratieniveaus is er tenslotte dat van de situationele verandering. Veranderingsstrategieën richten zich op het anders doen functioneren van de participanten.

\section{Beheersing van crises, dilemma's en conflicten}

Door een geoperationaliseerde afstemming van alle tot nog toe genoemde strategieën: de technologische, de ecologische en de sociale, kan er een instrumen. tarium worden gecreëerd, waarmee de organisatie haar dynamiek in toom kan houden. De katalysator is de dreiging van min of meer ernstige overlevingscrises. Het stabiliseren van open organisatiesystemen in dynamische, complexe en conflictgeladen omgevingen is in feite het voortdurend afwenden van crises rondom de dan geldende essentiële, d.i. strategische variabelen. Crises, die zich vanuit de informatieproblematiek manifesteren in dilemma's met betrekking tot besluitvorming en die zich vanuit de zingevingsproblematiek uiten in sociale conflicten.

Vgl March en Simon, 1958, pp. 89 e.v. en pp. 52 e.v.

15) Chester Barnard. The Functions of the Executive. Cambridge. Harvard University Press, 1964 (oorspr. 1938), p. 168 
Het organisatiebeeld, dat vanuit de genoemde drie werkelijkheidsdimensies te voorschijn komt, is allerminst van een gedetermineerd karakter. $\mathrm{Er}$ is een zekere vrijheid van handelen in stand gehouden. Dat is op te vatten als ruimte voor een dialectisch proces, waarin de organisationele werkelijkheid ,the incarnation of hu. man action" is, maar ook ,a reality which human action has to take as given"26). Daarmee is het dingmatige karakter van de organisatie, onlosmakelijk als dat ver. bonden was aan het decisie- en actiemodel, overwonnen. Het standpunt van alle participanten is theoretisch verwerkt. ,Managerial problem solving” maakt plaats voor „organizational problem solving”. Overigens een ontwikkeling ook in practi. sche zin: er zijn in de moderne organisatie aanwijzingen waarneembaar, die gaan in de richting van toenemende de-reificatie. Dat houdt in, dat de verschillende so. ciale actors elkaar minder als rollendragers beschouwen, maar zich wederzijds meer en meer laten aanspreken op hun persoon. Een groot winstpunt voor zin. geving in organisaties en voor de legitimatie van organisationeel gedrag.

\section{Naar een strategische theorie van organisatie-ontwikkeling}

Met dit in één bedding brengen van drie subparadigma's tot een realistisch or. ganisatiebeeld is mijns inziens tevens de weg geopend naar een strategische theorie van organisatie-ontwikkeling. Daarmee is het begrip strategisch management verbreed tot een op elkaar afgestemde aandacht voor zowel externe strategie met be. trekking tot de domeinkeuze van activiteiten als de interne strategie met betrekking tot een complexe, contingente en conflictgeladen structuur. Daarmee kan de organisatie zich extern en intern zodanig differentiëren, dat een ontwikkeling naar die mate van georganiseerde complexiteit in stand wordt gehouden, nodig voor doelmatigheid, overleving en zingeving van haar gedrag ${ }^{27}$ ).

\footnotetext{
26) Peter Berger en Stanley Pullberg. Reification and the Sociological Critique of Consciousness. New Left Review, 1966 (jan. feb) No 35, pp 56.71. Vgl ook Peler L. Berger en Thomas Luckmann. The Social Construction of Realit): A Treatise in the Sociology of Knowtedge New York. Doubleday (Anchor Books), 1967 (oorspr. 1966)

27) Dit is verder uirgewerkt in Haselhoff, 1977, hoofdstuk 5
} 